\title{
Soluble organic matter in the urban soils of Rostov agglomeration
}

Gorbov S., Skripnikov P., Bezuglova O., Tischenko S.

Southern Federal University, Rostov-on-Don, Russia, sngorbov@sfedu.ru

Keywords: Urbic Technosol, Chernozem, soluble organic matter

doi: 10.36291/HIT.2019.gorbov.029

The soil organic matter investigation is a necessary stage for solving many problems related to the effective soil resources exploitation and forecasting the techno-pedogenesis effects. Humus plays the major role in soil formation. On the one hand, it is very dynamic and sensitive to changes in the environment and/or anthropogenic impacts. On the other hand, it is a conservative part of a soil that has a certain tolerance towards disturbing impacts and can preserve its ecological status in the city conditions.

The aim of this paper was to discuss the specifics of accumulation and migration of soluble organic matter (SOM) through soil profile. The most mobile fraction of soil humus was isolated by cold and hot distilled water extraction according [1]. The SOM fraction was determined on a TOC-L CPN Shimadzu carbon analyzer with the solid sample combustion unit SSM-5000A.

The most typical soils were selected from seven soil profiles to identify patterns. All studied soils were divided into two groups depending on the level of transformation: natural soils (Haplic Chernozems (Calcic)) and anthropogenic soils (Urbic Technosols).

Haplic Chernozems (Calcic) are characterized by high humus content, but large amount of humic acids is strongly associated with calcium. As a result, SOM takes only a small part of soil organic matter and usually do not exceeding $0.14 \%$ for soil in whole, which corresponds to $4.0 \%$ in terms of $\mathrm{C}$ org. These values are much lower for Urbic horizons of anthropogenic soils and amounts to $0.04 \%$ to soil or about $2.0 \%$ in terms of $C$ org. Natural soils are characterized by a smooth decline absolute and relative SOM values down the profile. In individual cases there is a slight accumulation of SOM was observed for carbonate barrier in horizon $\mathrm{B}$. These processes are noted for soils with high content of total humus in surface humus accumulative horizons under forest vegetation where migration organic matter in the soil profile is most pronounced. Anthropogenic soils are characterized by a morphological two-fold profile. The upper part is represented by Urbic horizons, lower part is buried Haplic Chernozems, often deprived of upper horizon A to a depth of $20-30 \mathrm{~cm}$. As a result, Urbic Technosols is characterized by the chaotic distribution of SOM in anthropogenic thickness and a smooth decline in the buried chernozem thickness. Besides, long-term conservation of soil profile under impermeable coatings contributed to lack accumulation of SOM into the carbonate barrier in the lower part of the profile.

Acknowledgement. This research was supported by project of Ministry Education and Science of Russia, no. 6.6222.2017/8.9. Analytical work was carried out on the equipment of Centers for Collective Use of Southern Federal University "Biotechnology, Biomedical and Environmental Monitoring" and "High Technology".

References

1. Gregorich E.G. et al. // Geoderma. 2003. 113, 237-252. 